\title{
Effects of Heterogeneity within Tree Crowns on Airborne-Quantified SIF and the CWSI as Indicators of Water Stress in the Context of Precision Agriculture
}

\author{
Carlos Camino (1), Pablo J. Zarco-Tejada * and Victoria Gonzalez-Dugo \\ Instituto de Agricultura Sostenible (IAS), Consejo Superior de Investigaciones Científicas (CSIC), \\ Alameda del Obispo s/n, 14004 Cordoba, Spain; caminoccg@gmail.com (C.C.); \\ victoria.gonzalez@ias.csic.es (V.G.-D.) \\ * Correspondence: pablo.zarco@csic.es; Tel.: +34-676-954-937
}

Received: 1 March 2018; Accepted: 10 April 2018; Published: 13 April 2018

\begin{abstract}
This research focused on understanding the effects of structural heterogeneity within tree crowns on the airborne retrieval of solar-induced chlorophyll fluorescence (SIF) and the Crop Water Stress Index (CWSI). We explored the SIF and CWSI variability observed within crowns of trees subjected to different water stress regimes and its effect on the relationships with leaf physiological measurements. High-resolution $(20 \mathrm{~cm})$ hyperspectral imagery was acquired to assess fluorescence retrieval from sunlit portions of the tree crowns using the Fraunhofer line depth method, and from entire crowns using automatic object-based tree crown detection methods. We also measured the canopy temperature distribution within tree crowns using segmentation algorithms based on temperature percentiles applied to high-resolution $(25 \mathrm{~cm})$ thermal imagery. The study was conducted in an almond orchard cultivated under three watering regimes in Cordoba, in southern Spain. Three airborne campaigns took place during the summer of 2015 using high-resolution hyperspectral and thermal cameras on board a manned aircraft. Relationships between SIF and the assimilation rate improved significantly when the sunlit tree crown pixels extracted through segmentation were used for all flight dates. By contrast, the SIF signal extracted from the entire tree crowns was highly degraded due to the canopy heterogeneity observed within tree crowns. The quartile crown segmentations applied to the thermal images showed that the CWSI values obtained were within the theoretically expected CWSI range only when the pixels were extracted from the 50th percentile class. However, the CWSI values were biased in the upper quartile $\left(Q_{75}\right)$ for all watering regimes due to the soil background effects on the calculated mean crown temperature. The relationship between the CWSI and Gs was heavily affected by the crown segmentation levels applied and improved remarkably when the CWSI values were calculated from the middle quartile crown segmentation $\left(\mathrm{Q}_{50}\right)$, corresponding to the coldest and purest vegetation pixels $\left(\mathrm{r}^{2}=0.78\right.$ in pure vegetation pixels vs. $\mathrm{r}^{2}=0.52$ with the warmer pixels included in the upper quartile). This study highlights the importance of using high-resolution hyperspectral and thermal imagery for pure-object segmentation extractions from tree crowns in the context of precision agriculture and water stress detection.
\end{abstract}

Keywords: hyperspectral; thermal imagery; chlorophyll fluorescence; SIF; CWSI; photosynthetic activity; stomatal conductance; tree crown segmentation

\section{Introduction}

Water deficits occur in crops when the evaporative demand exceeds the supply of soil water [1]. As a result, plant growth and its physiological processes are affected [2]. Particularly, water stress reduces photosynthetic activity and induces stomatal closure. Consequently, evaporative cooling 
is reduced and canopy temperature increases. Besides the increase of temperature experienced by plants under water stress, the steady-state chlorophyll fluorescence emission (i.e., solar-induced fluorescence, SIF) is also affected due to the reduction of photosynthesis [3-5]. At the leaf scale, relationships between SIF and the assimilation rate vary due to the stress conditions [6-8] but also due to irradiance levels, temperature, nutritional status, and other environmental factors. For the purpose of characterizing plant water status, various field-level physiological measurements such as leaf water potential, stomatal conductance, and net assimilation are currently used. However, these leaf-level measurements are time consuming and therefore very restricted for operational purposes, especially when the aim is to characterize the spatial patterns of the physiological processes and within-field water status variability across an entire orchard. Therefore, finding adequate strategies for monitoring the within-field variability of physiological conditions is critical in the context of precision agriculture and for precision irrigation purposes. In this regard, image-based remote sensing methods based on innovative indicators directly linked to plant functioning are considered useful for the adequate monitoring of photosynthetic status and water stress in crops.

Recent studies have successfully demonstrated that image-based remote quantification of SIF is directly associated with the photosynthetic rate for detecting vegetation stress [9-12]. Although the use of narrow bands has been proposed for accurate retrieval of SIF in absolute terms (i.e., below $1 \mathrm{~nm}$ FWHM), recent studies have demonstrated that airborne hyperspectral imagery acquired with broader bandwidths $(5-7 \mathrm{~nm})$ still captures the fluorescence signal, which makes it possible to monitor photosynthesis over time $[13,14]$.

The high heterogeneity observed within tree crowns and the large effects caused by soil background and sunlit/shaded areas must be considered due to their influence on the SIF signal quantified from remote sensing imagery. The acquisition of very high resolution hyperspectral imagery enables the extraction of the SIF signal from each crown component, assessing the large effects caused by the canopy structure. In fact, the effects of canopy architecture have been the focus of several studies using hybrid models [15] and 3D simulation [16]. The use of three-dimensional (3D) information on a canopy structure based on airborne full-waveform Light Detection and Ranging (LiDAR) to characterize canopy structure $[17,18]$ is a promising field of research that may provide valuable information about the canopy architecture and the high heterogeneity observed within tree crowns. Nevertheless, no studies have explored the effects of within-crown structure on SIF quantification or the relationship of such effects with photosynthesis.

In the context of thermal imaging for detecting water stress, several studies have shown that high-resolution thermal imagery acquired from manned and unmanned aerial platforms enables the detection of water stress, showing accurate relationships with stomatal conductance [19-22] and water potential [23-25]. Yet, within-crown structure also plays a critical role in the quantification of crown temperature and in the relationships obtained with physiological measures. In fact, some studies have demonstrated that crown heterogeneity is a reliable tool for the early detection of plant water stress $[26,27]$. The variability of within-tree temperature and its relationship with water status can be due to several factors. At the individual tree level, stomatal closure related to water stress increases the overall canopy temperature and is affected by the water supply. In addition, it is well known that changes in leaf angle distribution, radiation exposure, leaf area density, and canopy architecture affect the variability of canopy temperature within crowns. Other factors, such as soil water and nutritional deficit [28] as well as the effect of diseases [29] also lead to differences in crown canopy temperature. As crown temperature is affected by the tree structure, the thermal-based indicator known as the Crop Water Stress Index (CWSI) [30,31] is also affected. The CWSI is based on the difference between canopy temperature and air temperature (Tc-Ta), normalized by the vapor pressure deficit (VPD), and is inversely related to transpiration and stomatal conductance [31]. Thus, within-tree structural variability plays a role in the relationships between the CWSI and stomatal conductance used to detect water stress. Moreover, external effects due to the surrounding non-vegetation targets may play a role in the quantified tree-level CWSI and its relationship with physiological measures. 
The research presented in this manuscript was carried out in an almond orchard subjected to different water stress regimes due to the regulated deficit irrigation levels imposed. The goal of this study was to assess within-tree structural effects on chlorophyll fluorescence and on the mean temperature quantified from high-resolution hyperspectral and thermal images in the context of water stress detection and precision irrigation. In addition, we explored the influence of tree structure and the background on the relationships between SIF and the field-measured assimilation rate, and the CWSI and stomatal conductance.

\section{Materials and Methods}

\subsection{Study Site and Field Data Collection}

The experiment was performed in July and August 2015 in an almond orchard subjected to regulated deficit irrigation treatments and a plot under rainfed $(\mathrm{RF})$ conditions. The experimental site was located in Cordoba, in southern Spain, at the Alameda del Obispo Research Station $\left(37^{\circ} 52^{\prime} \mathrm{N}\right.$, $\left.4^{\circ} 49^{\prime} \mathrm{W}\right)$. The climate is Mediterranean with mild winters and warm and dry summers. A weather station located at $300 \mathrm{~m}$ from the experimental site collected an average of air temperature of $18.6^{\circ} \mathrm{C}$ and relative humidity of $62 \%$ along the 2015 year. Annual rainfall and reference evapotranspiration (ETo; Penman-Monteith) were 330 and $1250 \mathrm{~mm}$, respectively. In this research, three watering regimes were analyzed: a rainfed plot was compared to plots subjected to two irrigated treatments, a fully irrigated control (FI), where irrigation fulfilled crop water requirements, and a severely regulated deficit irrigation treatment (RDI, which received 20\% ETc during the period comprised in this study. The irrigated treatments were replicated four times using a randomized block design (Figure 1). The orchard was drip irrigated with two lateral pipes per almond tree row and kept free of weeds, pests, and diseases. For more information about the experimental design and the irrigation levels, see López-López et al. [32].

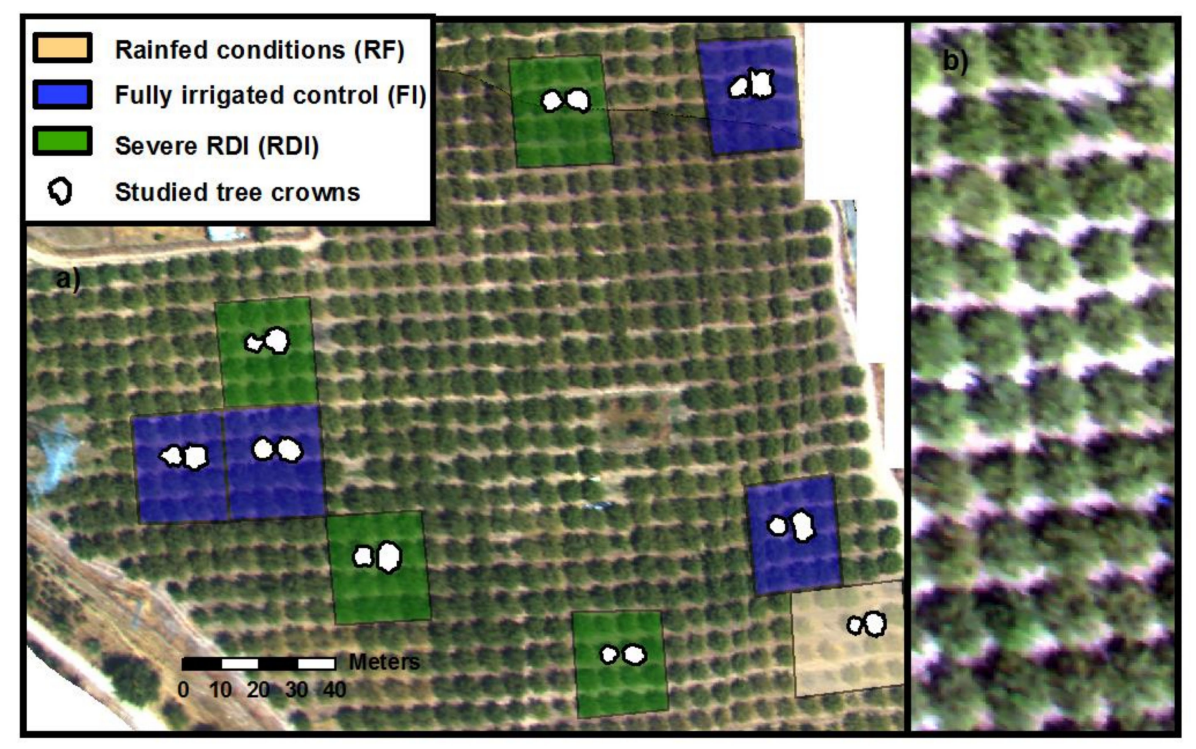

Figure 1. Overview of the almond orchard experimental site imaged by the hyperspectral sensor, showing the four replicates of the irrigated treatments and the rainfed condition plot (a). The central almond trees (in white) used to collect leaf measurements are shown. A detail view is displayed in (b).

The almond trees located in the center of each plot were measured to monitor their physiological status at the time of the flight (Figure 1$)$. Field measurements of assimilation rate $\left(\mathrm{A} ; \mu \mathrm{mol} \cdot \mathrm{m}^{-2} \cdot \mathrm{s}^{-1}\right)$ and stomatal conductance (Gs; $\mathrm{mmol} \cdot \mathrm{m}^{-2} \cdot \mathrm{s}^{-1}$ ) were collected from two/four leaves per tree (from six trees in the first flight and 18 trees in the other flights); the devices used were a photosynthesis 
measurement system (LCDpro-SD, ADC Bioscientific Ltd., Herts, UK) and a leaf porometer (SC-1, Decagon Devices Inc., Pullman, WA, USA), respectively.

\subsection{Airborne Campaigns}

Three airborne campaigns were performed on 1st July (day of the year DOY 182), 5th August (DOY 217) and 25th August (DOY 237) in 2015. We used a micro-hyperspectral imager (Micro-Hyperspec VNIR model, Headwall Photonics, Fitchburg, MA, USA) and a thermal infrared camera (FLIR SC655, FLIR Systems, Wilsonville, OR, USA) set in tandem on board a Cessna aircraft operated at $200 \mathrm{~m}$ altitude by the Laboratory for Research Methods in Quantitative Remote Sensing (QuantaLab) of the Spanish Council for Scientific Research (Consejo Superior de Investigaciones Científicas; IAS-CSIC, Córdoba, Spain). After each flight, the thermal and hyperspectral imagery was processed in the QuantaLab-IAS-CSIC laboratory.

The Micro-Hyperspec VNIR was set up with a configuration of 260 spectral bands acquired at $1.85 \mathrm{~nm} /$ pixel and 12-bit radiometric resolution in the 400-885 $\mathrm{nm}$ spectral region, yielding a $6.4 \mathrm{~nm}$ full width at half maximum (FWHM) with a $25-\mu \mathrm{m}$ slit. The acquisition and storage module achieved 50 frames per second at $25 \mathrm{~ms}$ integration time. The 8-mm focal length lens yielded an IFOV of 0.93 mrad and an angular FOV of $50^{\circ}$ with a spatial resolution of $20 \mathrm{~cm}$ (Figure 2a). The radiometric calibration was performed in the laboratory using coefficients derived from an integrating sphere (CSTM-USS-2000C LabSphere, North Sutton, NH, USA) at four levels of illumination and six integration times. The hyperspectral imagery was atmospherically corrected using the irradiance (E) measured at the time of the flight by means of an ASD Field Spectrometer (FieldSpec Handheld Pro, ASD Inc., Longmont, Colorado, USA) with $3 \mathrm{~nm}$ bandwidth and a cosine corrector-diffuser probe. The spectral resolution of the airborne imagery was matched with irradiance through a Gaussian convolution. The orthorectification of the hyperspectral imagery was performed using PARGE software (ReSe Applications Schläpfer, Wil, Switzerland) with input data acquired with an inertial measuring unit (IMU) installed on board and synchronized with the hyperspectral camera.

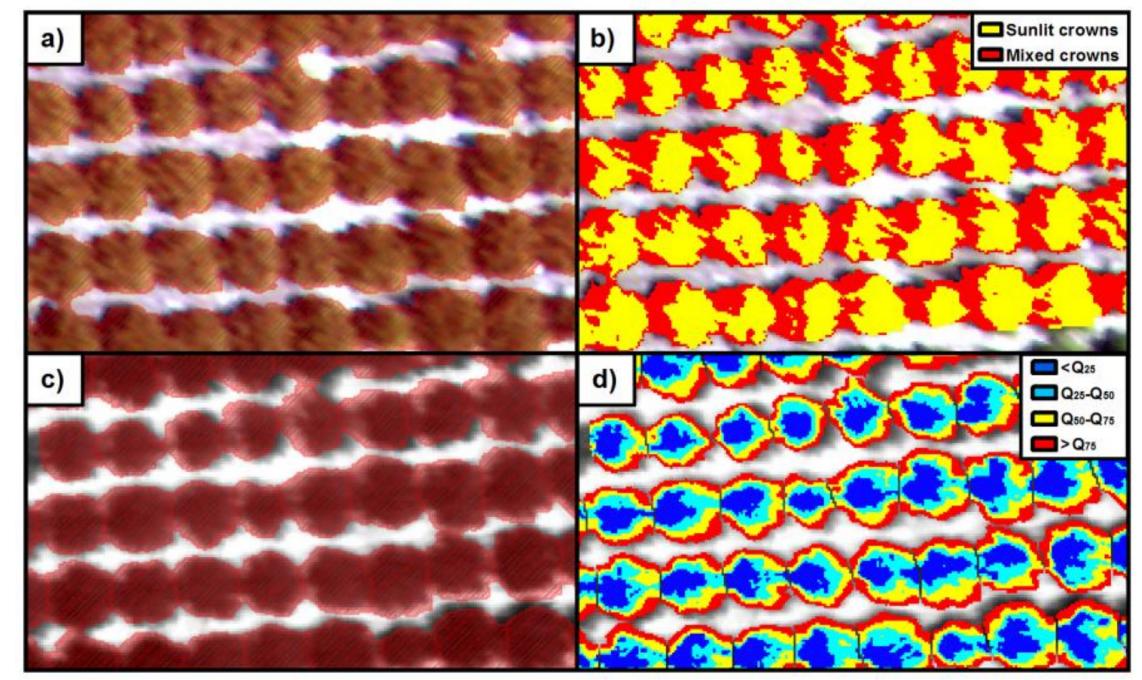

Figure 2. View of the entire crowns (in red with stripes) retrieved using automatic object-based crown detection applied to the imagery acquired with the Hyperspec VNIR (a) and thermal FLIR SC655 (c) cameras. The sunlit crowns (in yellow) and mixed crowns (in red) extracted from the hyperspectral imagery are shown in (b). The temperature segmentations based on quartile methods using thermal imagery are shown in $(\mathbf{d})$.

The thermal camera (FLIR SC655, FLIR Systems, Wilsonville, OR, USA) used in this study had a resolution of $640 \times 480$ pixels with a $13.1 \mathrm{~mm}$ focal length and 16 bit radiometric resolution, providing an angular FOV of $45 \times 33.7^{\circ}$, which yielded a ground resolution of $25 \mathrm{~cm}$ at the altitude of the flights 
(Figure 2c). The thermal imagery was calibrated using ground temperature data collected with a handheld infrared thermometer (LaserSight, Optris, Germany) on each flight date. The thermal imagery was processed and atmospherically corrected in the QuantaLab-IAS-CSIC laboratory [33,34].

\subsection{Within-Crown Segmentation Methods}

Each individual tree crown was segmented based on quartile breaks applied to the high-resolution hyperspectral and thermal imagery. The image segmentation was automatically conducted using in $\mathrm{R}$ software [35]. The methods to handle hyperspectral and thermal imagery and vector files were based on the "raster", "maptools", and "sp" packages [36-39] in R. An automatic object-based tree crown detection algorithm based on watershed segmentation (i.e., thresholds) using the "ClassInt" package [40] in $\mathrm{R}$ was applied to the hyperspectral imagery to separate almond crowns from the soil background. For each tree crown, the next step focused on separating the sunlit crown from the mixed crown area (i.e., the remaining tree crown, composed of soil contaminated pixels, shadows, and canopy background components) through spectral contrast analysis between sunlit/mixed pixels and background pixels. Tree crown hyperspectral reflectance $(\rho)$ was segmented through the following steps: (1) the normalized difference vegetation index (NDVI) [41] was used as a structural index to discriminate between sunlit vegetation and non-vegetation pixels [42]. Next, a NDVI threshold $\geq 0.55$ was used (Figure 2a); (2) taking advantage of the strong absorption of chlorophyll in the $677 \mathrm{~nm}$ band and the high reflectance at $800 \mathrm{~nm}$ produced by pure vegetation pixels, we normalized the difference between both regions using Equation (1). The normalized difference between the red and infrared regions using an automatic quartile break using the classIntervals function from "ClassInt" package was introduced to separate the mixed and sunlit areas within each tree crown (Figure 2b). This segmentation enabled us to identify the sunlit areas within entire crowns, separating them from shaded areas and pixels affected by background soil (due to low leaf area density).

$$
\frac{\left(\rho_{800}-\rho_{677}\right)-\operatorname{Min}\left(\rho_{800}-\rho_{677}\right)}{\operatorname{Max}\left(\rho_{800}-\rho_{677}\right)-\operatorname{Min}\left(\rho_{800}-\rho_{677}\right)}[0-1]
$$

Individual tree crown temperature was extracted from the high-resolution thermal imagery through image segmentation via automatic quartile breaks based on the temperature gradient. Using the same scheme as for the hyperspectral imagery, the watershed segmentation method was applied to separate the tree crown from the soil background. However, the watershed segmentation in the thermal imagery was applied using the Sauvola's thresholding method [43] based on the standard deviation and average from the entire image. Next, each tree crown was divided into four quartiles by automatic object-based crown detection using the classIntervals function from "ClassInt" package in R. The pixels of individual tree crowns were divided into four classes using the 25th, 50th, and 75th percentiles (Figure 3d). The proposed four classes comprised (i) pixels below the first quartile $\left(\mathrm{Q}_{25}\right)$, associated with the coldest and purest vegetation areas without soil background; (ii) pixels within quartile $\mathrm{Q}_{25}$ and the middle quartile $\left(\mathrm{Q}_{50}\right)$; (iii) pixels within $\mathrm{Q}_{50}$ and the upper quartile $\left(\mathrm{Q}_{75}\right)$; and (iv) pixels above the upper quartile $\left(Q_{75}\right)$, associated with the warmest areas mainly affected by the background soil.

\subsection{Sub-Crown SIF and CWSI Retrieval Calculated from the High-Resolution Imagery}

Single-tree crown radiance and reflectance spectra were extracted from the high-resolution hyperspectral imagery. The solar-induced chlorophyll fluorescence (SIF) signal was retrieved using the Fraunhofer line depth (FLD) principle [44]. According to the method described in [9,14,45], the mean object-based radiance (L) for each tree crown calculated from the hyperspectral data and the irradiance obtained by the field ASD spectrometer at the time of the flight were used to quantify SIF. The retrieval method was based on two spectral bands located inside $(762 \mathrm{~nm})$ and outside $(750 \mathrm{~nm})$ of the $\mathrm{O}_{2}-\mathrm{A}$ absorption feature $[45,46]$ (see Figure 4a). SIF was extracted from the entire tree crowns and the sunlit areas within each tree crown (Figure 3b). SIF quantified from the trees of the experiment was 
compared to the leaf-level measurements of net photosynthesis acquired at the time of the flight for each date. In addition, following a similar methodology to that proposed by Zarco-Tejada et al. [47], a normalization scheme was applied to all trees and dates to compare the relationship between SIF and assimilation rates for water stress detection on the flight dates. The normalized SIF was calculated by dividing each within-tree object-level SIF value by the maximum value of FI (i.e., non-stressed trees) for each single date.

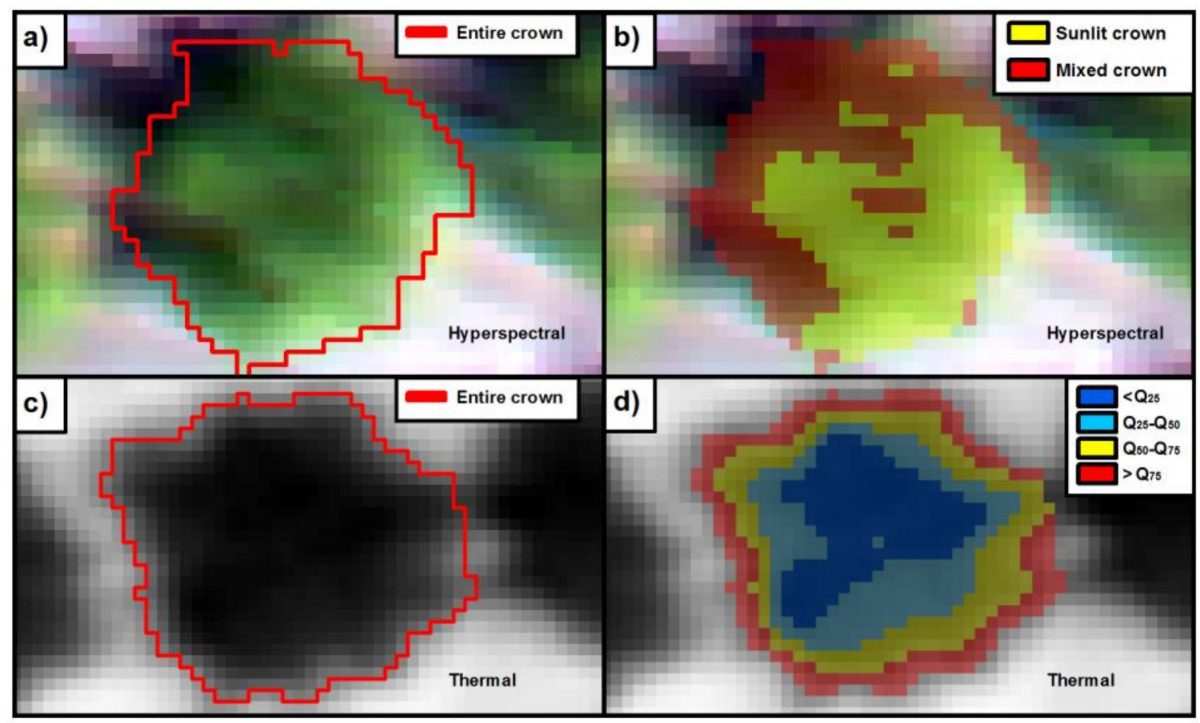

Figure 3. View of an entire tree crown acquired with the hyperspectral (a) and the thermal camera (c). Identification of the sunlit crown and the mixed crown components in the hyperspectral (b) and the thermal imagery (d).
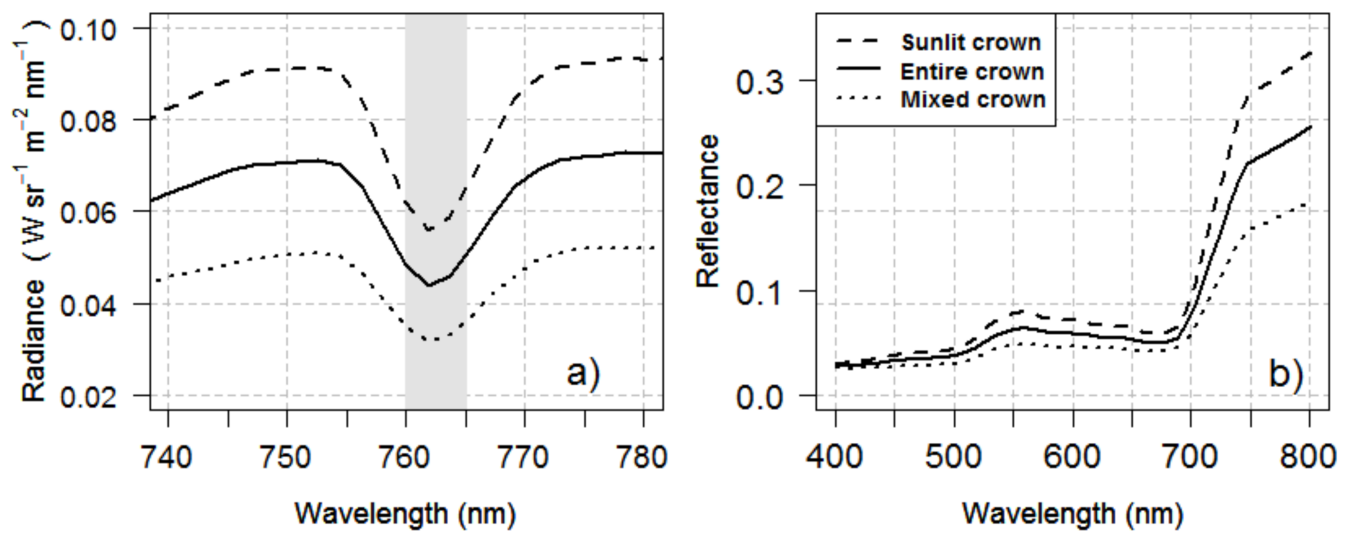

Figure 4. Radiance spectra in $\mathrm{W} \cdot \mathrm{sr}^{-1} \cdot \mathrm{m}^{-2} \cdot \mathrm{nm}^{-1}$ (a) and the corresponding reflectance spectra (b) for sunlit, mixed and entire crown targets retrieved from the high-resolution hyperspectral imagery during the second flight. The displayed spectra correspond to a tree crown under severe RDI. The vertical grey region in (a) shows the $\mathrm{O}_{2}-\mathrm{A}$ atmospheric oxygen absorption band.

Based on the temperature quartile segmentation (Figure 3d), the CWSI was retrieved from the thermal imagery as a water stress indicator of the almond tree crowns. The average canopy tree crown temperature (Tc) extracted from the thermal imagery, air temperature (Ta), and relative humidity was used to calculate the CWSI according to the methodology proposed by Idso et al., 1981 [30]. Theoretical CWSI boundaries are 0 (no water stress) and 1 (maximum water stress). The CWSI was compared with the field measurements of stomatal conductance acquired at the time of the flight on the various dates. 


\section{Results}

\subsection{Field Physiological Measurements}

Figure 5 shows the relationship between the assimilation rate $\left(A ;\right.$ in $\left.\mu \mathrm{mol} \cdot \mathrm{m}^{-2} \cdot \mathrm{s}^{-1}\right)$ and stomatal conductance (Gs; in $\mathrm{mmol} \cdot \mathrm{m}^{-2} \cdot \mathrm{s}^{-1}$ ) as well as the temporal changes experienced by each physiological indicator as a function of the water stress treatments. Table 1 shows the separability between treatments for A and Gs using an analysis of variance (ANOVA) F test followed by Tukey's HSD (honest significant difference) test. This table summarizes the basic statistics for the physiological measurements. As shown in Figure 5a, the assimilation rate was linearly related to the stomatal conductance for the three flight dates. In general, for all flight dates, the physiological status showed higher values for FI than for RDI and RF treatments (Figure 5b,c). At the time of the three flights, the field physiological measurements taken at the leaf level from almond trees under RF conditions were kept below $1.8 \mu \mathrm{mol} \cdot \mathrm{m}^{-2} \cdot \mathrm{s}^{-1}$ for $\mathrm{A}$ and $106 \mathrm{mmol} \cdot \mathrm{m}^{-2} \cdot \mathrm{s}^{-1}$ for Gs, indicating that these trees were severely affected by water stress. Meanwhile, trees subjected to the FI treatment yielded the highest average stomatal conductance and assimilation rate on all flight dates.
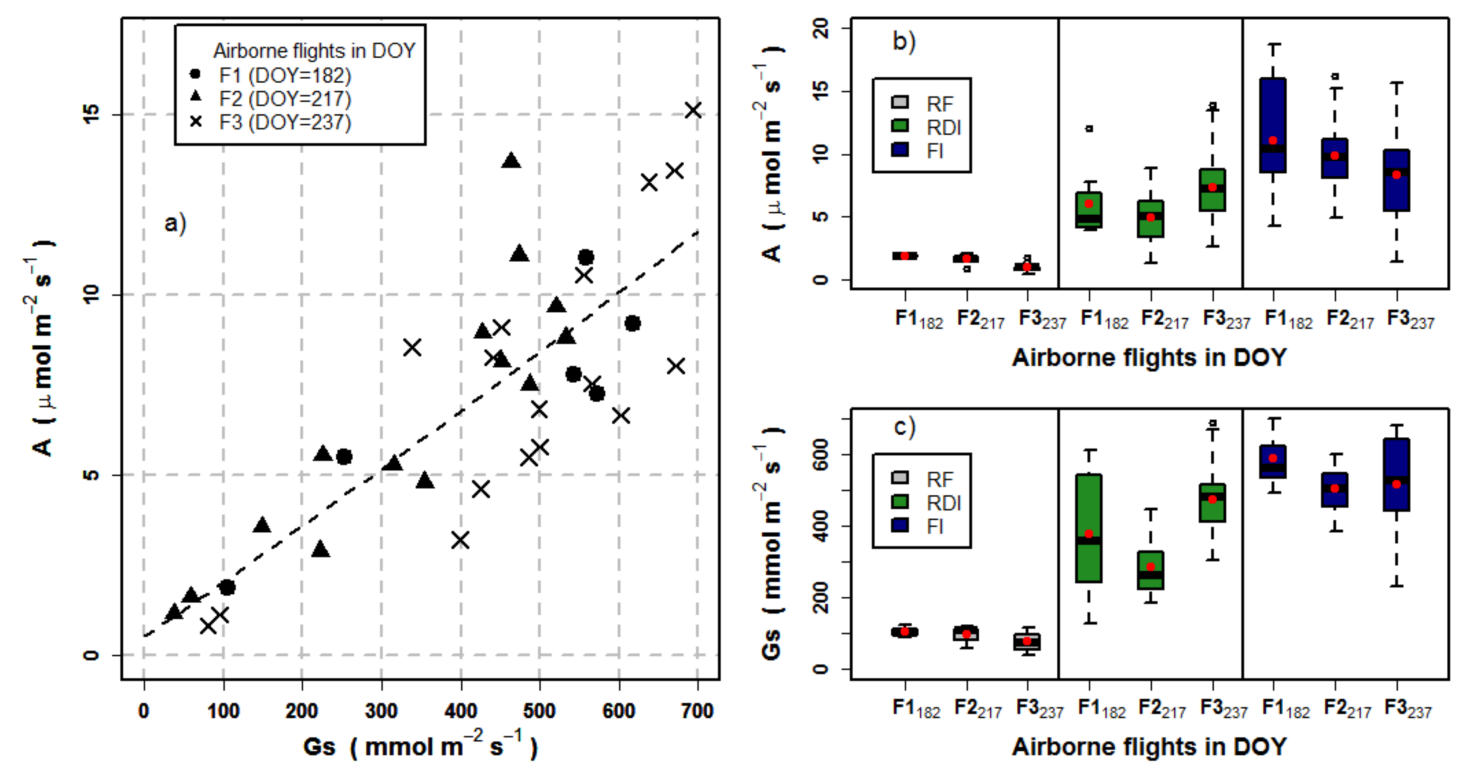

Figure 5. Scatter plot obtained between field assimilation rate $\left(\mathrm{A} ; \mu \mathrm{mol} \cdot \mathrm{m}^{-2} \cdot \mathrm{s}^{-1}\right)$ and stomatal conductance (Gs; in $\left.\cdot \mathrm{mmol} \cdot \mathrm{m}^{-2} \cdot \mathrm{s}^{-1}\right)$ for each flight date (F1-F3) (a). The boxplots show the A (b) and Gs (c) variability registered on rainfed $(\mathrm{RF})$, severe regulated deficit irrigation (RDI) and full irrigation (FI) for each flight date (F1-F3). In the boxplots, the average values are shown with a red point. The black line within the box is the median, and the top and bottom of the box is the 75th and 25th quartile, respectively. The whiskers represent the upper and the lower limits based on the difference with the interquartile ranges $(\mathrm{Q} \pm 1.5 \times \mathrm{IQR})$. The outliers represented as asterisk correspond to values out of upper and lower limits.

The results of the ANOVA showed significant differences in Gs and A between all irrigation treatments for each flight date; these differences were greater in the flight performed on DOY 217 $\left(\right.$ F-value $=65.37$ and 68.33 for A and Gs, respectively; both with $p$-values $\left.\leq 2.82 \times 10^{-12}\right)$. Tukey's HSD post-hoc analysis showed statistically significant differences in Gs between almond trees subjected to rainfed and irrigated treatments for each flight date ( $p$-value $<0.05)$. However, there were no differences in assimilation rate between the two irrigated treatments on DOY 237. 
Table 1. Average assimilation rate $\left(\mathrm{A} ; \mu \mathrm{mol} \cdot \mathrm{m}^{-2} \cdot \mathrm{s}^{-1}\right)$ and stomatal conductance $\left(\mathrm{Gs} ; \mathrm{mmol} \cdot \mathrm{m}^{-2} \cdot \mathrm{s}^{-1}\right)$ measured for each water regime and flight date. F statistic and $p$-value obtained from the standard analysis of variance (ANOVA).

\begin{tabular}{|c|c|c|c|c|c|c|}
\hline & \multicolumn{3}{|c|}{ Mean \pm SD } & \multicolumn{2}{|c|}{ ANOVA } & \multirow[t]{2}{*}{ Tukey } \\
\hline \multicolumn{6}{|l|}{ A } & \\
\hline & RF & RDI & FI & F-value & $p$-value & $p$-value \\
\hline Flight 1 (DOY = 182) & $1.87^{\mathrm{a}}$ & $6.05^{b} \pm 2.7$ & $11.1^{\mathrm{c}} \pm 5.0$ & 4.762 & 0.0238 & $<0.05$ \\
\hline Flight $2(\mathrm{DOY}=217)$ & $1.60^{\mathrm{a}} \pm 0.3$ & $5.04^{b} \pm 1.6$ & $9.82^{\mathrm{c}} \pm 2.7$ & 65.37 & $<2 \times 10^{-16}$ & $<0.001$ \\
\hline Flight 3 (DOY = 237) & $1.0^{\mathrm{a}} \pm 0.4$ & $7.40^{b} \pm 2.5$ & $8.30^{b} \pm 3.9$ & 20.15 & $8.48 \times 10^{-8}$ & $<0.001$ * \\
\hline \multicolumn{7}{|l|}{ Gs } \\
\hline & $\mathrm{RF}$ & RDI & FI & F-value & $p$-value & $p$-value \\
\hline Flight $1(\mathrm{DOY}=182)$ & $105.6^{\mathrm{a}} \pm 18.2$ & $377.4^{b} \pm 159.2$ & $587.7^{\mathrm{c}} \pm 82.1$ & 22.53 & $1.06 \times 10^{-6}$ & $<0.001$ \\
\hline Flight $2(\mathrm{DOY}=217)$ & $96.0^{\mathrm{a}} \pm 31.4$ & $285.1^{\mathrm{b}} \pm 78.0$ & $504.5^{c} \pm 60.2$ & 68.33 & $2.82 \times 10^{-12}$ & $<0.001$ \\
\hline Flight $3(\mathrm{DOY}=237)$ & $76.6^{a} \pm 27.7$ & $473.3^{b} \pm 93.5$ & $523.6^{c} \pm 202.4$ & 28.18 & $9.11 \times 10^{-10}$ & $<0.05$ \\
\hline
\end{tabular}

Notes: RF, RDI and FI correspond to rainfed, severe regulated deficit irrigation and full irrigation, respectively. Treatments sharing the same letter are not significantly different in Tukey's honest significant difference (HSD) post-hoc test. $\mathrm{SD}=$ standard deviation. The * indicates significant differences between RF and the irrigated treatments. Letters $(a, b$ and $c)$ represent the results of Tukey's post-hoc comparisons of group means.

\subsection{Within-Crown SIF and CWSI Variability as a Function of Water Stress}

The object-based crown segmentation methods applied to the hyperspectral imagery to separate sunlit from mixed regions within tree crowns (Figures $3 \mathrm{~b}$ and 4 ) made it possible to assess the coefficient of variation (CV; Table 2) as a function of water stress levels. These results indicated that the sunlit crown portions showed more homogeneity in pixel variability for all water stress regimes on each flight date. By contrast, entire crowns had more heterogeneity due to the mixture of sub-crown components such as pure vegetation, shaded areas, and soil effects. As a result of within-crown variability, SIF yielded a higher CV for entire crowns than for sunlit crowns, as expected (Table 2). It is interesting to note that the CV for sunlit crowns was higher in RDI than in FI and RF treatments. By contrast, the CV for entire crowns increased with higher values of water stress. Overall, SIF showed higher average values in sunlit crowns than in entire crowns. Moreover, SIF differences between treatments increased when the sunlit areas were considered. In general terms, the average SIF signal was higher in the FI treatment, followed by the RDI and finally the RF treatment for both entire and sunlit crown segmentations. However, the mean fluorescence signal calculated from pixels of entire tree crowns was highly degraded compared to the SIF of sunlit crowns due to the effects of the mixed fractional canopy on each pixel (Table 2). In these situations, the SIF emission caused a decrease in radiance values in the range close to the $\mathrm{O}_{2}$-A absorption peak (Figure 4a), compared to the SIF signal when the sunlit crown segmentations were conducted. Moreover, as shown on Table 2, the SIF signal was more affected by the atmospheric conditions on each flight date for all studied water stress regimes than it was by the canopy temperature extracted from thermal imagery. Regarding the reflectance profiles, the pixels from sunlit crowns showed reflectance values higher in the near infrared region (Figure $4 \mathrm{~b}$ ) as compared to pixels from mixed crowns (shaded areas, branches and soil background). However, entire crowns, which correspond to the aggregation of pixels from sunlit and mixed crowns, are displayed between sunlit crown and mixed crown radiance and reflectance (Figure 4). 
Table 2. Average values and coefficient of variation (CV) of solar-induced chlorophyll fluorescence (SIF) and canopy temperature (Tc) retrieved from tree crown segmentation for each water stress regime and flight date. RF, RDI and FI correspond to rainfed, severe regulated deficit irrigation and full irrigation, respectively. The Tc value is divided into four quartile classes based on the 25th, 50th, and 75th quartiles (Q).

\begin{tabular}{|c|c|c|c|c|c|c|}
\hline & \multicolumn{6}{|c|}{ Average Values (CV, Coefficient of Variation) } \\
\hline & \multicolumn{2}{|c|}{ SIF } & \multicolumn{4}{|c|}{ Temperature (Tc in $\mathrm{K})$} \\
\hline & $\begin{array}{l}\text { Entire } \\
\text { crowns }\end{array}$ & $\begin{array}{l}\text { Pure veg. } \\
\text { pixels }\end{array}$ & $<Q 25$ & Q25-Q50 & Q50-Q75 & $>$ Q75 \\
\hline \multicolumn{7}{|c|}{ Flight 1 (DOY = 182) } \\
\hline $\mathrm{RF}$ & $2.43(0.17)$ & $2.67(0.08)$ & $308.1(0.01)$ & $308.7(0.02)$ & $309.8(0.05)$ & $315.1(0.03)$ \\
\hline RDI & $2.73(0.20)$ & $3.11(0.17)$ & $304.7(0.05)$ & $305.2(0.05)$ & $306.0(0.07)$ & $311.1(0.06)$ \\
\hline FI & $3.06(0.26)$ & $3.55(0.11)$ & $303.1(0.03)$ & $303.5(0.03)$ & $304.1(0.04)$ & $309.1(0.06)$ \\
\hline \multicolumn{7}{|c|}{ Flight 2 (DOY = 217) } \\
\hline RF & $2.94(0.11)$ & $2.99(0.09)$ & $309.5(0.01)$ & $310.4(0.01)$ & $311.8(0.01)$ & $314.1(0.02)$ \\
\hline RDI & $3.85(0.15)$ & $4.22(0.11)$ & $304.9(0.04)$ & $306.0(0.04)$ & $307.4(0.03)$ & $310.2(0.04)$ \\
\hline FI & $4.21(0.16)$ & $4.71(0.08)$ & $303.3(0.03)$ & $304.1(0.02)$ & $305.2(0.03)$ & $308.0(0.05)$ \\
\hline \multicolumn{7}{|c|}{ Flight $3(\mathrm{DOY}=237)$} \\
\hline $\mathrm{RF}$ & $1.25(0.22)$ & $1.41(0.15)$ & $308.9(0.01)$ & $311.0(0.01)$ & $313.6(0.02)$ & $316.8(0.02)$ \\
\hline RDI & $1.88(0.34)$ & $2.25(0.21)$ & $305.3(0.04)$ & $306.5(0.04)$ & $308.8(0.05)$ & $313.0(0.05)$ \\
\hline FI & $1.86(0.36)$ & $2.32(0.20)$ & $304.3(0.03)$ & $305.4(0.03)$ & $307.0(0.04)$ & $311.2(0.06)$ \\
\hline
\end{tabular}

The mean Tc values increased from $<Q_{25}$ to $>Q_{75}$. In addition, when average values for the four classes were compared for each flight and treatment, the difference between $Q_{50}-Q_{75}$ and $Q_{75}$ was higher than between the other pairs of ranges, indicating that $Q_{75}$ was substantially different (Table 2). Looking at the spatial pattern of the range obtained within each tree crown (located on the crown edges, Figure 3d), it can be observed that the effects of background and soil pixels on the average value were the main drivers of these differences. Overall, the average canopy temperature was greater in the RF treatment than in the RDI treatment, which was in turn higher than in FI. Similarly to what was observed for the CV of SIF values obtained from sunlit crowns, the variability of canopy temperature for all classes (except for $>Q_{75}$ ) displayed an increasing value between FI and RDI treatments and then decreased for RF trees.

These quartile segmentation methods enabled the characterization of the temperature distribution within individual tree crowns but also of its effects on the CWSI. The assessment of the CWSI, as a normalized indicator, enabled the comparison of the canopy temperature between dates and also between ranges. In the almond trees of the experiment, the rainfed treatment resulted in increased stomatal closure, smaller crowns, and lower leaf density caused by the long-term water stress imposed. As a consequence, the CWSI values obtained were close to the theoretical maximum value of 1 (Figure 6), even for $\mathrm{Q}_{25}$. Considering the overall high temperature retrieved in all quartiles, it seems that the CWSI values recorded for RF trees were more affected by soil background compared to severe RDI and FI trees (Table 2). The NDVI values retrieved for these trees agreed with this observation (data not shown). The quartile crown segmentations also showed that CWSI values were biased in the $\mathrm{Q}_{50}-\mathrm{Q}_{75}$ range and upper quartile $\left(>\mathrm{Q}_{75}\right)$ for all watering regimes, as consequence of soil background effects (Figure 6). As a result, mean CWSI values were shifted beyond the maximum of the theoretical CWSI limit (i.e., CWSI > 1), even for trees subjected to RF conditions in the $\mathrm{Q}_{25}-\mathrm{Q}_{50}$ quartile classes with smaller crowns. Overall, CWSI values retrieved from the two lower classes ( $\leq 50$ th percentile) were within the theoretical CWSI range for the irrigated regimes. The aggregation of pixels of the two classes below the 50th percentile resulted in values that may explain the observation and physiological measurements: the average values remained within the expected $0-1$ range, indicating that pure vegetation pixels were targeted with little contamination from the soil background. The CWSI obtained from RF trees displayed an average value of 1.05, slightly above the maximum. In trees subjected to the FI and RDI treatments, the CWSI values obtained were 0 and 0.30 , respectively. 


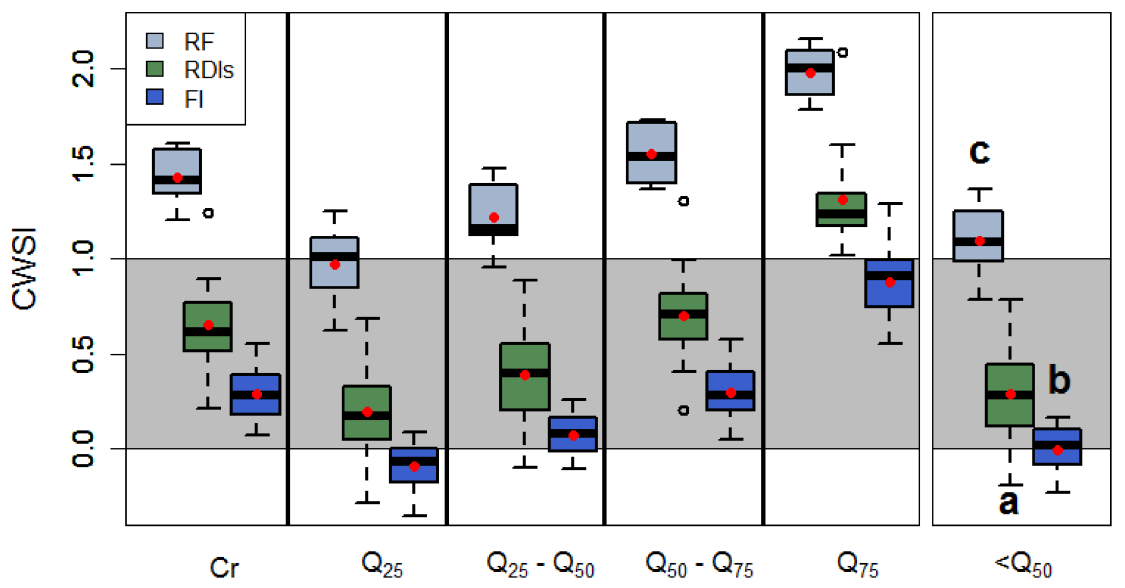

Figure 6. Box plot showing the airborne-quantified Crop Water Stress Index (CWSI) from entire crowns $(\mathrm{Cr})$, the quartile classes separated using the 25th, 50th and 75th percentiles and the aggregated quartile classes $\left(Q_{25}\right.$ and $\left.Q_{25}-Q_{50}\right)$ for the water regimes of the experiment. RF, RDI and FI correspond to rainfed, severe regulated deficit irrigation and full irrigation, respectively. The grey shading corresponds to the theoretical CWSI limits between 0 and 1 . Average values are shown with a red point. In the box plots, the black line within the box is the median, the top and bottom of the box is the 75th and 25th quartile respectively. The whiskers represent the upper and lower limits based on the difference with the interquartile ranges $(\mathrm{Q} \pm 1.5 \times \mathrm{IQR})$. The outliers represented as circles, correspond to values out of upper and lower limits. Treatments sharing the same letter were not significantly different in Tukey's HSD post-hoc test ( $p$-value $<0.0005)$.

\subsection{Effects of Crown Segmentation on Relationships between SIF and Assimilation}

The average SIF quantified from each tree crown was correlated with the mean assimilation rate across all dates for the entire crown and for the sunlit crown pixel selection. Results were statistically significant $\left(\mathrm{r}^{2}>0.66, p\right.$-value $\left.<0.005\right)$ across all dates for both crown segmentation levels (Figure 7). Results slightly improved when the sunlit crown segmentations were used (Figure $7 \mathrm{~b}$ ). The range of variation for the SIF values extracted from entire crowns became narrower and shifted towards lower SIF levels (Figure 7c), as a consequence of the mixture of soil background and shaded areas. The changes observed in SIF retrieval were related to the contribution of shaded areas and background effects to the overall SIF signal quantified from the entire crown.
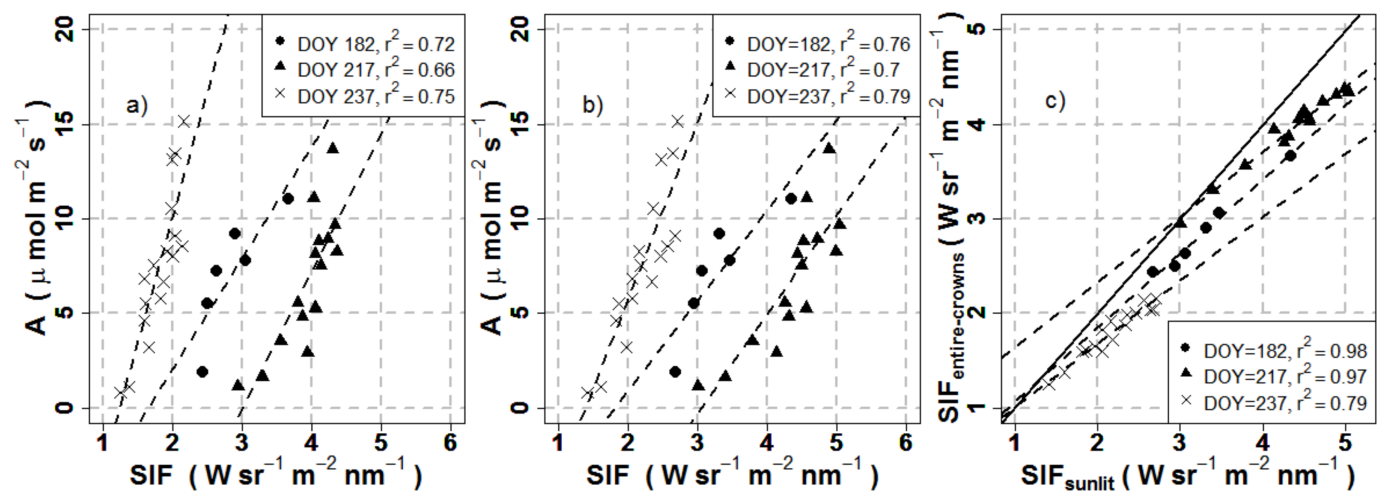

Figure 7. Relationships found on single dates between leaf net assimilation rate and airborne chlorophyll fluorescence (SIF) for entire tree crowns (a) and sunlit tree crowns (b). Relationships between SIF extracted from entire tree crowns and sunlit tree crowns (c) for single dates. 
The relationship between the fluorescence signal and the net assimilation for entire and sunlit crowns was different for each flight date (Figure 7). A method based on the normalization of SIF for each tree to the non-water stressed SIF value for each date yielded a single relationship between SIF and A on the three flights conducted throughout the season (Figure 8a). The normalized SIF extracted from the sunlit crown segmentations yielded a slight better relationship with $\mathrm{A}\left(\mathrm{r}^{2}=0.66 ; p\right.$-value $<0.0005$ and residual standard error $=2.17)$ than that of entire crowns $\left(\mathrm{r}^{2}=0.56 ; p\right.$-value $<0.0005$, residual standard error $=2.45$ ). These results demonstrated the improved sensitivity to A when the sunlit pixel component was used both on individual dates and normalizing across the entire season.

The separability among water stress treatments according to the seasonally-normalized SIF assessed via an ANOVA and Tukey's post-hoc analysis (Table 3) showed a statistically significant difference between the means of the water stress regimes. Tukey's post-hoc analysis showed statistically significant differences between FI and RDI ( $p$-value $<0.05$ ) for sunlit crown segmentations, while the seasonally-normalized SIF extracted from entire crowns did not show any differences between them. In particular, Figure $8 \mathrm{~b}$ shows that differences between treatments in the median and the average of the normalized SIF were greater when it was extracted from sunlit crown segmentations than when it was derived from entire crowns. As a result, the SIF signal extracted from sunlit pixels was able to track the physiological changes due to the water stress regimes imposed.

Table 3. ANOVA and Tukey's HSD post-hoc analysis of normalized solar-induced chlorophyll fluorescence values extracted from pure sunlit crowns and entire crowns for each water stress treatment. RF, RDI and FI correspond to rainfed, severe regulated deficit irrigation and full irrigation, respectively.

\begin{tabular}{ccccc}
\hline & \multicolumn{2}{c}{ ANOVA } & \multicolumn{2}{c}{ Tukey's Test } \\
\hline & F-value & $p$-value & T-value & $p$-value \\
\hline Entire crowns & 16.39 & $9.55 \times 10^{-3}$ & & \\
FI-RF & $\ldots$ & $\ldots$ & 5.720 & $<1 \times 10^{-4}$ \\
FI-RDI & $\ldots$ & $\ldots$ & -2.030 & 0.1169 \\
RF-RDI & $\ldots$ & $\ldots$ & 4.225 & 0.000468 \\
\hline Pure sunlit crowns & 20.25 & $1.44 \times 10^{-6}$ & & \\
FI-RF & $\ldots$ & $\ldots$ & 6.338 & $<0.001$ \\
FI-RDI & $\ldots$ & $\ldots$ & -2.534 & 0.0399 \\
RF-RDI & $\ldots$ & $\ldots$ & 4.489 & $<0.001$ \\
\hline
\end{tabular}
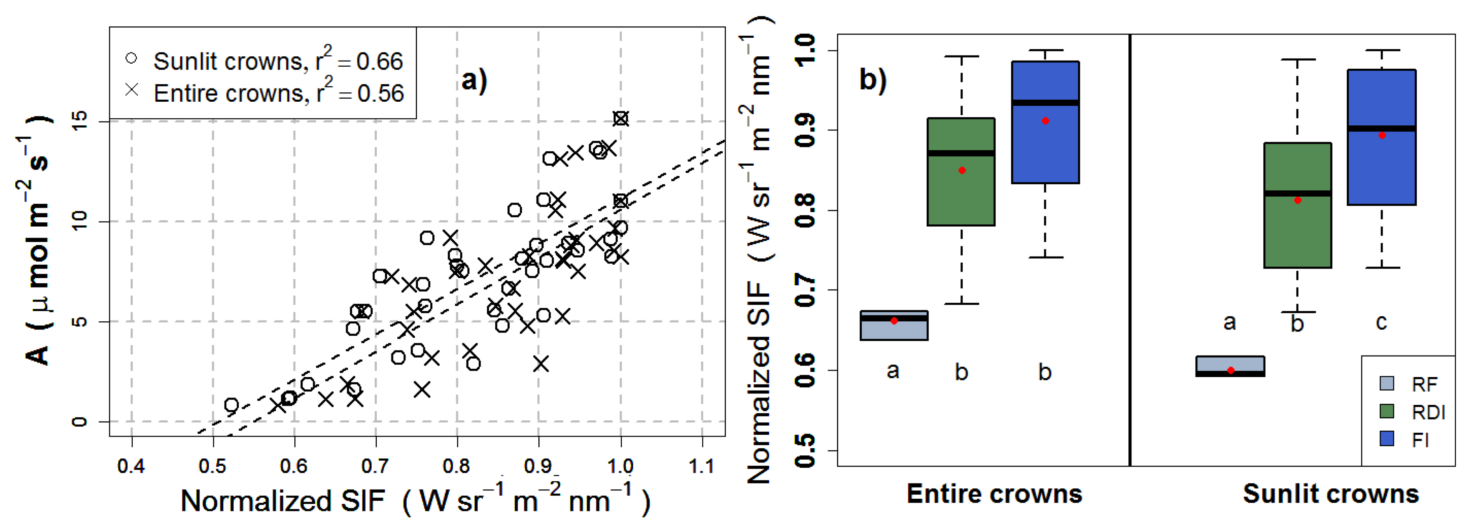

Figure 8. Relationships found between leaf assimilation and normalized airborne-quantified chlorophyll fluorescence for entire and pure sunlit crowns (a). Box plot of normalized SIF retrieved from entire crowns and pure sunlit crowns for the water stress regimes explored $(\mathbf{b})$. The mean value is represented with a red point. For each segmentation, treatments sharing the same letter were not significantly different in Tukey's HSD post-hoc test ( $p$-value $<0.05)$. 


\subsection{Effects of Crown Segmentation on the Relationships between the CWSI and Stomatal Conductance}

The average CWSI quantified from each tree crown was compared to mean stomatal conductance across all dates for all crown segmentation levels based on temperature quartile thresholds. The results in Figure 9a show that the CWSI was linearly and inversely correlated with stomatal conductance. The relationships showed large effects due to the quartile-crown segmentations applied: CWSI values extracted from the upper quartile $\left(>Q_{75}\right)$ shifted towards high values of the CWSI due to the soil background effects; by contrast, in the lower half $\left(<\mathrm{Q}_{50}\right)$ and entire crown pixels, CWSI values were lower than 1 for the irrigated regimes. Relationships with Gs improved remarkably when CWSI values corresponded to the coldest and purest vegetation areas associated to the first quartile $\left(<\mathrm{Q}_{25}\right)$ and pixels from the lower half quartile $\left(<Q_{50}\right)$, yielding an $r^{2}=0.77$ and $r^{2}=0.78$, respectively. However, the agreement with field-measured stomatal conductance yielded a weaker coefficient of determination for $>Q_{75}\left(r^{2}<0.52, p\right.$-value $\left.<0.005\right)$. Figure $9 \mathrm{~b}$ shows the displacement between quartile classes in the lower half $\left(<Q_{50}\right)$, which obtained the best results with Gs. Quartile-crown segmentations with a greater mixture of shaded and background pixels within tree-crowns were placed above the 1:1 line, compared to segmentations associated with the coldest and purest vegetation areas, which were close to the $1: 1$ line.
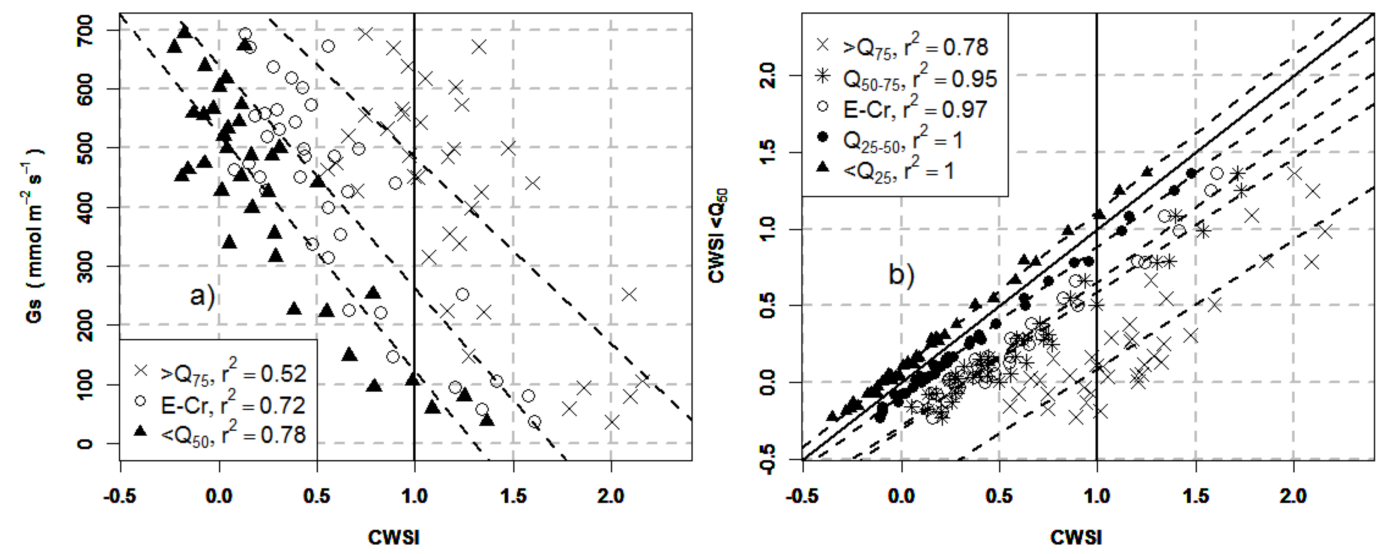

Figure 9. Relationships found between leaf stomatal conductance (Gs) and the CWSI by extracting pixels from entire crowns (E-Cr), pixels below the middle quartile $\left(<\mathrm{Q}_{50}\right)$, and pixels in the upper quartile $\left(>Q_{75}\right)$ for all flight dates (a). Relationships between CWSI pixels extracted from the middle quartile class $\left(<\mathrm{Q}_{50}\right)$ and all quartile-crown and entire tree crown segmentations explored (b). Solid black line represents the line 1:1, and dashed lines are fit lines for the studied quartile masks and entire crown mask.

The separability among water stress treatments via the ANOVA F-test and Tukey's HSD test (Table 4) showed statistically significant differences in the CWSI ( $p$-value $<0.0005)$ between all the treatments explored, indicating that CWSI derived from high-resolution thermal imagery was able to separate between almond trees under different water regimes.

Table 4. ANOVA and Tukey's HSD post-hoc analysis of the CWSI extracted from quartile segmentations for each water stress treatment. RF, RDI and FI correspond to rainfed, severe regulated deficit irrigation and full irrigation, respectively.

\begin{tabular}{ccccc}
\hline & \multicolumn{2}{c}{ ANOVA } & \multicolumn{2}{c}{ Tukey's Test } \\
\hline & F-value & $p$-value & T-value & $p$-value \\
\hline$<$ Q50 & 60.28 & $4.6 \times 10^{-12}$ & 60.28 & $4.6 \times 10^{-12}$ \\
FI-RF & $\ldots$ & $\ldots$ & -10.944 & $<1 \times 10^{-4}$ \\
FI-RDI & $\ldots$ & $\ldots$ & 4.283 & 0.000383 \\
RF-RDI & $\ldots$ & $\ldots$ & -7.814 & $<1 \times 10^{-4}$ \\
\hline
\end{tabular}




\section{Discussion}

This study explored the effects of within-tree crown variability on airborne-based fluorescence retrievals and the CWSI as indicators of water stress. The range of variation in water status observed in this experiment, ranging from well-watered to rainfed conditions, enabled the assessment of stress detection performance of the remote sensing indicators when different segmentation methods were applied to high-spatial resolution hyperspectral and thermal images. This methodology made it possible to assess the effects caused by shadows and background on the fluorescence and thermal indicators used for water stress detection. Sunlit vegetation and entire crowns were used to quantify the fluorescence signal, while temperature quartiles were used as a segmentation method for the canopy thermal imagery. It is important to note that the segmentation methods were applied automatically, minimizing the influence of the operator to identify the regions of interest.

Previous studies have demonstrated that the SIF signal and its relationship with the assimilation rate is reduced under complex canopy structures and with background soil effects [15]. In this study, SIF retrievals extracted from entire crowns were affected by shadows, structural, and background soil effects, masking changes in fluorescence amplitude caused by the physiological condition. The results presented here show that chlorophyll fluorescence retrieval was highly degraded due to the effects of structure, leaf density, sunlit/shaded areas, and soil background. As shown in Figure $4 a$, when the entire crown was used, the radiance magnitude was reduced in the range close to the $\mathrm{O}_{2}-\mathrm{A}$ absorption peak, compared to sunlit pixels within the tree crowns. This result is in agreement with Hernández-Clemente et al. [16], who demonstrated that SIF emission extracted from sunlit crown pixel radiance was greatly affected by the increasing contribution of shaded and background pixels. In this study, within-tree crown heterogeneity was confirmed by the higher coefficient of variation observed in the SIF retrievals extracted from entire crowns (Table 2) for all watering regimes. By contrast, lower $\mathrm{CV}$ values of SIF were obtained from the sunlit crown segmentation areas, which are associated to vegetation pixels without soil contamination. The heterogeneity of the shaded and sunlit areas within almond tree crowns modulated the relationship between airborne fluorescence and assimilation rates. As shown in Figure 7, the relationships between fluorescence and assimilation varied as a function of stress level and atmospheric conditions on each flight date. However, as shown on Table 2, water stress reduced airborne SIF retrievals, yielding a relative mean SIF that was lower in crowns of trees subjected to RF conditions than in those irrigated trees. This result is consistent with $[10,48]$, who demonstrated that the SIF signal is sensitive to plant water stress.

Daumard et al. [49] showed that atmospheric impacts on SIF retrievals should be taken into account. This issue was observed in Figure 7, which shows a changing relationship between the assimilation rate and the SIF quantified on different dates. The changes in the slope and amplitude of the relationships with the assimilation rate that are shown in the figure were due to several reasons: (i) the SIF emission was affected by atmospheric scattering effects (i.e., aerosol optical depth, aerosol height, surface albedo, and surface pressure) when the $\mathrm{O}_{2}$-A absorption band at $760 \mathrm{~nm}$ was used to estimate the fluorescence emission [50]. Although the Fraunhofer method reduced the atmospheric scattering effects using bands close to the oxygen absorption band, these scattering effects were still present; (ii) the fluorescence signal was modulated not only by the irradiance levels but also by the water stress and ambient conditions imposed during the different flight dates; and (iii) the inherent offsets of the SIF approach created when it was calculated from broader bandwidth hyperspectral imagery (i.e., 5-7 nm FWHM), which generated absolute errors in the quantification of the SIF signal. For these reasons, specific strategies are required for the proper use of chlorophyll fluorescence measurements in precision agriculture.

Following a normalization SIF scheme, fluorescence emission was normalized by the maximum fluorescence signal emitted by the control well-watered almond trees, which served as a reference. The relationship obtained between the normalized fluorescence emission and the field-measured assimilation rate was linear and yielded better results when the sunlit crown segmentation was applied $\left(\mathrm{r}^{2}=0.66\right)$. Our approach confirmed the feasibility of using the normalized fluorescence signal as 
an indicator of photosynthetic activity throughout the season. In this research, we also showed that normalized SIF retrieval was lower under rainfed conditions than under irrigated regimes in both tree crown segmentations explored (Figure 8 b). This result is consistent with previous studies [6,8,51] that have shown that water stress induces changes in chlorophyll fluorescence emission. In this study, the ANOVA and Tukey's HSD post-hoc test (Table 3) confirmed that the normalized SIF retrieval extracted from sunlit areas within tree crowns was able to separate the three water stress regimes analyzed (as was observed with the physiological measurements); by contrast, the normalized SIF extracted from entire crowns showed no differences between the irrigated treatments. These results highlight the need for high-resolution hyperspectral imagery to extract the SIF signal from sunlit vegetation within tree-crowns.

Other studies have shown that thermal imaging reveals spatial heterogeneity within tree crowns [52,53] or between plant canopies [54,55], which can be used as an indicator to monitor stress conditions. These studies have reported that the heterogeneity of canopy temperature is a reliable tool for tracking the water status using thermal airborne imagery. However, few studies have focused on the assessment of the variability of thermal airborne indicators within tree crowns, probably due to the high resolution needed to accomplish this task. In this regard, Gonzalez-Dugo et al. [52] demonstrated that the mean canopy temperature in almond trees affects the relationship between intra-crown temperature variability and water potential. In fact, they demonstrated that the variability of crown temperature was higher in almond trees subjected to intermediate irrigation levels compared to well-watered ones and to trees subjected to the most water stressed treatments. In that case, canopy architecture and soil background temperature had an influence as the temperature was extracted for entire tree crowns. However, in the present study we extracted pure pixels. We analyzed CWSI variability between different crown areas and its relationship with stomatal conductance measured at the leaf level. The central part of the crowns displayed lower temperature values, which were associated to pure vegetation without soil contamination. However, in some cases the pattern of the temperature distribution associated to pure vegetation may shift towards other crown areas due to changes caused by the density of vegetation canopy, crown structural effects, leaf angle distribution, leaf area index, and the solar angle at the time of flight. The assessment of the CWSI as a temperature-derived normalized index allowed us to account for the environmental conditions at the time of acquisition and also to assess the thermal information from the three flight dates. Moreover, the calculation of the CWSI enabled the assessment of the area that better described overall plant performance, avoiding the contamination of soil background.

This study shows that pixels contained in crown areas below the 50th percentile $\left(<\mathrm{Q}_{25}\right.$ and $\mathrm{Q}_{25}-\mathrm{Q}_{50}$ ) corresponded to pure vegetation pixels without soil background effects (Figure $3 \mathrm{~d}$ ), compared to pixels included into the $Q_{50}-Q_{75}$ and $Q_{75}$ quartile classes associated with pixels with soil contamination and with low leaf densities. These results explained the high average CWSI values displayed when pixels extracted from $Q_{50}-Q_{75}$ and $Q_{75}$ segmentations were used (Figure 6), an effect observed in all treatments (Table 2). As a result, the mean CWSI values reached the upper out-of-range limit. Overall, the CWSI retrieved from the lower half quartile $\left(<\mathrm{Q}_{50}\right)$ was within the theoretical CWSI range for the irrigated treatments and rainfed regime. However, the mean CWSI value recorded in $\mathrm{RF}$ trees for $\mathrm{Q}_{25}-\mathrm{Q}_{50}$ was slightly above the maximum theoretical CWSI value. This bias was due to the effect of soil background related to the low leaf area density. According to the ANOVA F-test followed by Tukey's HSD post-hoc analysis (Table 4$)$, the aggregated quartile classes $\left(<\mathrm{Q}_{50}\right)$ displayed the required accuracy to identify the differences under different water regimes.

The relationships obtained between the CWSI and field-measured stomatal conductance were statistically significant $(p$-value $<0.005)$ and well correlated, yielding weaker relationships with stomatal conductance for the upper quartile-crown segmentations $\left(Q_{75}\right)\left(r^{2}=0.62\right)$. This inverse relationship with Gs yielded robust statistical results when the CWSI was extracted from pixels below the middle quartile $\left(\mathrm{r}^{2}=0.78\right.$ and $p$-value $\left.<0.005\right)$. The good agreement with stomatal conductance confirms that the CWSI can be used as a stress indicator in precision agriculture 
applications. In agreement with recent studies [56,57], this research also showed that the CWSI is a reliable tool for monitoring the spatial variability of water stress using high-resolution thermal imagery. Furthermore, our results provide a detailed quantification of the spatial variability of the crown temperature within almond tree crowns and identify an automatic procedure for improving the accuracy for monitoring water status in orchard tree crops.

\section{Conclusions}

This study demonstrates the large effects caused by within-tree structural variability and background on the airborne-derived SIF and CWSI physiological indicators used for water stress detection. Results highlight the importance of collecting high-resolution hyperspectral and thermal imagery in orchard crops to enable targeting pure crown-level vegetation pixels. The crown segmentation methods applied to extract sunlit vegetation crown areas improved the relationships between SIF and field-measured leaf assimilation rate. The SIF retrievals carried out using sunlit vegetation pixels minimized the impact of canopy structure and reduced the soil background effects, enabling a better detection of water stress. In the thermal imagery, the crown segmentation methods demonstrated that within-crown shadows and the background affected CWSI. When entire tree crowns were used, the CWSI values obtained fell outside the expected theoretical range of variation, affecting the relationship with stomatal conductance.

Acknowledgments: The experiment was carried out in the experimental farm "Alameda del Obispo" belonging to IFAPA. The authors gratefully acknowledge the financial support of the Spanish Ministry of Science and Education for projects AGL2012-40053-C03-01 and AGL2012-35196 and of the Regional Government of Andalusia, Spain, for project P12-AGR-2521. Ignacio Lorite and Elías Fereres are acknowledged for their support to this work. The authors would also like to thank R. Romero, D. Notario, A. Vera, and A. Hornero for their technical support during the airborne campaign and the image processing conducted in the QuantaLab-IAS-CSIC laboratory. M. López-López, M. Orgaz, K. Gutiérrez, and R. Luque are also acknowledged for their fieldwork in the almond orchard.

Author Contributions: P.J.Z.-T., V.G.-D. and C.C. conceived, designed, and coordinated the study. C.C. carried out the field data acquisition. C.C. processed the hyperspectral and thermal remote sensing data and conducted the statistical analyses. C.C., P.J.Z.-T., and V.G.-D. wrote the manuscript and contributed text and figures for it.

Conflicts of Interest: The authors declare no conflict of interest.

\section{References}

1. Slatyer, R.O. Plant-Water Relationships; Academic Press: New York, NY, USA, 1967.

2. Hsiao, T.C. Plant Responses to Water Stress. Annu. Rev. Plant Physiol. 1973, 24, 519-570. [CrossRef]

3. Lichtenthaler, H.K.; Lang, M.; Sowinska, M.; Heisel, F.; Miehé, J.A. Detection of Vegetation Stress via a New High Resolution Fluorescence Imaging System. J. Plant Physiol. 1996, 148, 599-612. [CrossRef]

4. Lichtenthaler, H.K.; Rinderle, U. The Role of Chlorophyll Fluorescence in The Detection of Stress Conditions in Plants. CRC Crit. Rev. Anal. Chem. 1988, 19, S29-S85. [CrossRef]

5. Schreiber, U.; Bilger, W. Rapid assessment of stress effects on plant leaves by chlorophyll fluorescence measurements. In Plant Response to Stress: Functional Analysis in Mediterranean Ecosystems; Tenhunen, J.D., Catarino, F.M., Lange, O.L., Oechel, W.C., Eds.; Springer: Berlin/Heidelberg, Germany, 1987; pp. $27-53$.

6. Flexas, J.; Escalona, J.M.; Evain, S.; Gulías, J.; Moya, I.; Osmond, C.B.; Medrano, H. Steady-state chlorophyll fluorescence (Fs) measurements as a tool to follow variations of net $\mathrm{CO}_{2}$ assimilation and stomatal conductance during water-stress in C3 plants. Physiol. Plant. 2002, 114, 231-240. [CrossRef] [PubMed]

7. Flexas, J.; Briantais, J.M.; Cerovic, Z.; Medrano, H.; Moya, I. Steady-state and maximum chlorophyll fluorescence responses to water stress in grapevine leaves: A new remote sensing system. Remote Sens. Environ. 2000, 73, 283-297. [CrossRef]

8. Flexas, J.; Escalona, J.M.; Medrano, H. Water stress induces different levels of photosynthesis and electron transport rate regulation in grapevines. Plant Cell Environ. 1999, 22, 39-48. [CrossRef]

9. Meroni, M.; Colombo, R. Leaf level detection of solar induced chlorophyll fluorescence by means of a subnanometer resolution spectroradiometer. Remote Sens. Environ. 2006, 103, 438-448. [CrossRef] 
10. Pérez-Priego, O.; Zarco-Tejada, P.J.; Miller, J.R.; Sepulcre-Cantó, G.; Fereres, E. Detection of water stress in orchard trees with a high-resolution spectrometer through chlorophyll fluorescence In-Filling of the $\mathrm{O}_{2}-\mathrm{A}$ band. IEEE Trans. Geosci. Remote Sens. 2005, 43, 2860-2868. [CrossRef]

11. Porcar-Castell, A.; Tyystjärvi, E.; Atherton, J.; Van Der Tol, C.; Flexas, J.; Pfündel, E.E.; Moreno, J.; Frankenberg, C.; Berry, J.A. Linking chlorophyll a fluorescence to photosynthesis for remote sensing applications: Mechanisms and challenges. J. Exp. Bot. 2014, 65, 4065-4095. [CrossRef] [PubMed]

12. Rascher, U.; Alonso, L.; Burkart, A.; Cilia, C.; Cogliati, S.; Colombo, R.; Damm, A.; Drusch, M.; Guanter, L.; Hanus, J.; et al. Sun-induced fluorescence-A new probe of photosynthesis: First maps from the imaging spectrometer HyPlant. Glob. Chang. Biol. 2015, 21, 4673-4684. [CrossRef] [PubMed]

13. Damm, A.; Erler, A.; Hillen, W.; Meroni, M.; Schaepman, M.E.; Verhoef, W.; Rascher, U. Modeling the impact of spectral sensor configurations on the FLD retrieval accuracy of sun-induced chlorophyll fluorescence. Remote Sens. Environ. 2011, 115, 1882-1892. [CrossRef]

14. Damma, A.; Guanter, L.; Paul-Limoges, E.; van der Tol, C.; Hueni, A.; Buchmann, N.; Eugster, W.; Ammann, C.; Schaepman, M.E. Far-red sun-induced chlorophyll fluorescence shows cosystem-specific relationships to gross primary production: An assessment based on observational and modeling approaches. Remote Sens. Environ. 2015, 166, 91-105. [CrossRef]

15. Zarco-Tejada, P.J.; Suarez, L.; Gonzalez-Dugo, V. Spatial resolution effects on chlorophyll fluorescence retrieval in a heterogeneous canopy using hyperspectral imagery and radiative transfer simulation. IEEE Geosci. Remote Sens. Lett. 2013, 10, 937-941. [CrossRef]

16. Hernández-Clemente, R.; North, P.R.J.; Hornero, A.; Zarco-Tejada, P.J. Assessing the effects of forest health on sun-induced chlorophyll fluorescence using the FluorFLIGHT 3-D radiative transfer model to account for forest structure. Remote Sens. Environ. 2017, 193, 165-179. [CrossRef]

17. Dandois, J.P.; Ellis, E.C. High spatial resolution three-dimensional mapping of vegetation spectral dynamics using computer vision. Remote Sens. Environ. 2013, 136, 259-276. [CrossRef]

18. Hernández-Clemente, R.; Navarro-Cerrillo, R.M.; Romero Ramírez, F.J.; Hornero, A.; Zarco-Tejada, P.J.; Ramírez, F.J.R.; Hornero, A.; Zarco-Tejada, P.J. A novel methodology to estimate single-tree biophysical parameters from 3D digital imagery compared to aerial laser scanner data. Remote Sens. 2014, 6, 11627-11648. [CrossRef]

19. Gonzalez-Dugo, V.; Goldhamer, D.; Zarco-Tejada, P.J.; Fereres, E. Improving the precision of irrigation in a pistachio farm using an unmanned airborne thermal system. Irrig. Sci. 2015, 33, 43-52. [CrossRef]

20. Zarco-Tejada, P.J.; González-Dugo, V.; Williams, L.E.; Suárez, L.; Berni, J.A.J.J.; Goldhamer, D.; Fereres, E. A PRI-based water stress index combining structural and chlorophyll effects: Assessment using diurnal narrow-band airborne imagery and the CWSI thermal index. Remote Sens. Environ. 2013, 138, 38-50. [CrossRef]

21. Jones, H.G.; Serraj, R.; Loveys, B.R.; Xiong, L.; Wheaton, A.; Price, A.H. Thermal infrared imaging of crop canopies for the remote diagnosis and quantification of plant responses to water stress in the field. Funct. Plant Biol. 2009, 36, 978-989. [CrossRef]

22. Bendig, J.; Yu, K.; Aasen, H.; Bolten, A.; Bennertz, S.; Broscheit, J.; Gnyp, M.L.; Bareth, G. Combining UAV-based plant height from crop surface models, visible, and near infrared vegetation indices for biomass monitoring in barley. Int. J. Appl. Earth Obs. Geoinf. 2015, 39, 79-87. [CrossRef]

23. Bellvert, J. El uso de la Teledetección de alta Resolución como Herramienta para realizar un manejo eficiente del riego en viñedos. Ph.D. Thesis, Universidad de Córdoba, Córdoba, Spain, 2014.

24. Gonzalez-Dugo, V.; Zarco-Tejada, P.J.; Fereres, E. Applicability and limitations of using the crop water stress index as an indicator of water deficits in citrus orchards. Agric. For. Meteorol. 2014, 198-199, 94-104. [CrossRef]

25. Bellvert, J.; Marsal, J.; Girona, J.; Gonzalez-Dugo, V.; Fereres, E.; Ustin, S.L.; Zarco-Tejada, P.J. Airborne thermal imagery to detect the seasonal evolution of crop water status in peach, nectarine and Saturn peach orchards. Remote Sens. 2016, 8, 39. [CrossRef]

26. Fuchs, M. Infrared measurement of canopy temperature and detection of plant water stress. Theor. Appl. Climatol. 1990, 42, 253-261. [CrossRef]

27. Gardner, B.R.; Blad, B.L.; Watts, D.G. Plant and air temperatures in differentially-irrigated corn. Agric. Meteorol. 1981, 25, 207-217. [CrossRef] 
28. Rodriguez, D.; Sadras, V.O.; Christensen, L.K.; Belford, R. Spatial assessment of the physiological status of wheat crops as affected by water and nitrogen supply using infrared thermal imagery. Aust. J. Agric. Res. 2005, 56, 983-993. [CrossRef]

29. Calderón, R.; Navas-Cortés, J.A.; Lucena, C.; Zarco-Tejada, P.J. High-resolution airborne hyperspectral and thermal imagery for early detection of Verticillium wilt of olive using fluorescence, temperature and narrow-band spectral indices. Remote Sens. Environ. 2013, 139, 231-245. [CrossRef]

30. Idso, S.B.; Jackson, R.D.; Pinter, P.J.; Reginato, R.J.; Hatfield, J.L. Normalizing the stress-degree-day parameter for environmental variability. Agric. Meteorol. 1981, 24, 45-55. [CrossRef]

31. Jackson, R.D.; Idso, S.B.; Reginato, R.J.; Pinter, J.P.J. Canopy temperature as a crop water stress indicator. Water Resour. Res. 1981, 17, 1133-1138. [CrossRef]

32. López-López, M.; Espadador, M.; Testi, L.; Lorite, I.J.; Orgaz, F.; Fereres, E. Water use of irrigated almond trees when subjected to water deficits. Agric. Water Manag. 2018, 195, 84-93. [CrossRef]

33. Berni, J.; Zarco-Tejada, P.J.; Suarez, L.; Fereres, E. Thermal and Narrowband Multispectral Remote Sensing for Vegetation Monitoring from an Unmanned Aerial Vehicle. IEEE Trans. Geosci. Remote Sens. 2009, 47, 722-738. [CrossRef]

34. Zarco-Tejada, P.J.; González-Dugo, V.; Berni, J.A.J. Fluorescence, temperature and narrow-band indices acquired from a UAV platform for water stress detection using a micro-hyperspectral imager and a thermal camera. Remote Sens. Environ. 2012, 117, 322-337. [CrossRef]

35. R Core Team. R: A Language and Environment for Statistical Computing; R Foundation for Statistical Computing: Vienna, Austria, 2011; ISBN 3-900051-07-0.

36. Hijmans, R.J. raster: Geographic Data Analysis and Modeling. R package version 2.6-.7. Available online: http:/CRAN.R-project.org/package=raster (accessed on 10 January 2018).

37. Bivand, R.; Lewin-Koh, N. maptools: Tools for Reading and Handling Spatial Objects. R package version 0.9-2. Available online: http:/CRAN.R-project.org/package=maptools (accessed on 10 January 2018).

38. Pebesma, E.J.; Bivand, R.S. Classes and methods for spatial data in $\{R\} . R$ News 2005, 5, 9-13.

39. Bivand, R.S.; Pebesma, E.; Gomez-Rubio, V. Applied Spatial Data Analysis with $\{R\}, 2$ nd ed.; Springer: New York, NY, USA, 2013.

40. Bivand, R. classInt: Choose Univariate Class Intervals. R package version 0.1-24. Available online: http:/CRAN.R-project.org/package=classInt (accessed on 10 January 2018).

41. Rouse, J.W.; Hass, R.H.; Schell, J.A.; Deering, D.W. Monitoring vegetation systems in the great plains with ERTS. In Proceedings of the Third Earth Resources Technology Satellite Symposium, Washington, DC, USA, 10-14 December 1973; Volume 1, pp. 309-317.

42. Xiao, Q.; Ustin, S.L.; McPherson, E.G. Using AVIRIS data and multiple-masking techniques to map urban forest tree species. Int. J. Remote Sens. 2004, 25, 5637-5654. [CrossRef]

43. Sauvola, J.; Pietikäinen, M. Adaptive document image binarization. Pattern Recognit. 2000, 33, $225-236$. [CrossRef]

44. Plascyk, J.A.; Gabriel, F.C. The Fraunhofer line discriminator MKII an airborne instrument for precise and standardized ecological luminescence measurement. IEEE Trans. Instrum. Meas. 1975, 24, 306-313. [CrossRef]

45. Moya, I.; Camenen, L.; Evain, S.; Goulas, Y.; Cerovic, Z.G.; Latouche, G.; Flexas, J.; Ounis, A. A new instrument for passive remote sensing: 1. Measurements of sunlight-induced chlorophyll fluorescence. Remote Sens. Environ. 2004, 91, 186-197. [CrossRef]

46. Meroni, M.; Busetto, L.; Colombo, R.; Guanter, L.; Moreno, J.; Verhoef, W. Performance of Spectral Fitting Methods for vegetation fluorescence quantification. Remote Sens. Environ. 2010, 114, 363-374. [CrossRef]

47. Zarco-Tejada, P.J.; González-Dugo, M.V.; Fereres, E. Seasonal stability of chlorophyll fluorescence quantified from airborne hyperspectral imagery as an indicator of net photosynthesis in the context of precision agriculture. Remote Sens. Environ. 2016, 179, 89-103. [CrossRef]

48. Lee, J.-E.; Frankenberg, C.; van der Tol, C.; Berry, J.A.; Guanter, L.; Boyce, C.K.; Fisher, J.B.; Morrow, E.; Worden, J.R.; Asefi, S.; et al. Forest productivity and water stress in Amazonia: Observations from GOSAT chlorophyll fluorescence. Proc. R. Soc. B Biol. Sci. 2013, 280, 20130171. [CrossRef] [PubMed]

49. Daumard, F.; Goulas, Y.; Champagne, S.; Fournier, A.; Ounis, A.; Olioso, A.; Moya, I. Continuous monitoring of canopy level sun-induced chlorophyll fluorescence during the growth of a sorghum field. IEEE Trans. Geosci. Remote Sens. 2012, 50, 4292-4300. [CrossRef] 
50. Frankenberg, C.; Butz, A.; Toon, G.C. Disentangling chlorophyll fluorescence from atmospheric scattering effects in $\mathrm{O}_{2}$ A-band spectra of reflected sun-light. Geophys. Res. Lett. 2011, 38, 1-5. [CrossRef]

51. Zarco-Tejada, P.J.; Morales, A.; Testi, L.; Villalobos, F.J. Spatio-temporal patterns of chlorophyll fluorescence and physiological and structural indices acquired from hyperspectral imagery as compared with carbon fluxes measured with eddy covariance. Remote Sens. Environ. 2013, 133, 102-115. [CrossRef]

52. Gonzalez-Dugo, V.; Zarco-Tejada, P.; Berni, J.A.J.; Suárez, L.; Goldhamer, D.; Fereres, E. Almond tree canopy temperature reveals intra-crown variability that is water stress-dependent. Agric. For. Meteorol. 2012, 154-155, 156-165. [CrossRef]

53. Agam, N.; Segal, E.; Peeters, A.; Levi, A.; Dag, A.; Yermiyahu, U.; Ben-Gal, A. Spatial distribution of water status in irrigated olive orchards by thermal imaging. Precis. Agric. 2014, 15, 346-359. [CrossRef]

54. González-Dugo, M.P.; Moran, M.S.; Mateos, L.; Bryant, R. Canopy temperature variability as an indicator of crop water stress severity. Irrig. Sci. 2006, 24, 233-240. [CrossRef]

55. Grant, O.M.; Tronina, Ł.; Jones, H.G.; Chaves, M.M. Exploring thermal imaging variables for the detection of stress responses in grapevine under different irrigation regimes. J. Exp. Bot. 2007, 58, 815-825. [CrossRef] [PubMed]

56. Meron, M.; Tsipris, J.; Orlov, V.; Alchanatis, V.; Cohen, Y. Crop water stress mapping for site-specific irrigation by thermal imagery and artificial reference surfaces. Precis. Agric. 2010, 11, 148-162. [CrossRef]

57. Gonzalez-Dugo, V.; Hernandez, P.; Solis, I.; Zarco-Tejada, P.J. Using high-resolution hyperspectral and thermal airborne imagery to assess physiological condition in the context of wheat phenotyping. Remote Sens. 2015, 7, 13586-13605. [CrossRef]

(c) 2018 by the authors. Licensee MDPI, Basel, Switzerland. This article is an open access article distributed under the terms and conditions of the Creative Commons Attribution (CC BY) license (http://creativecommons.org/licenses/by/4.0/). 